\title{
INTERNET OF THINGS (IOT) SISTEM PENGENDALIAN LAMPU MENGGUNAKAN RASPBERRY PI BERBASIS MOBILE
}

\author{
Yoyon Efendi
}

\author{
Program Studi Teknik Informatika \\ STMIK Amik Riau
}

Jl. Purwodadi Indah Km. 10 Pekanbaru

yoyonfendi@stmik-amik-riau.ac.id

\begin{abstract}
Abstrak
Internet of thing (IoT) merupakan suatu konsep yang bertujuan untuk memperluas manfaat dari konektivitas internet yang tersambung secara terus menerus. Internet of thing (IoT) bisa dimanfaatkan pada gedung untuk mengendalikan peralatan elektronik seperti lampu ruangan yang dapat dioperasikan dari jarak jauh melalui jaringan komputer. Penelitian ini bertujuan untuk membangun perangkat remote control dengan memanfaatkan teknologi internet untuk melakukan proses pengendalian lampu berbasis mobile. Penelitian dilakukan dengan membangun sebuah prototype dan aplikasi berbasis mobile menggunakan bahasa pemrograman python. Dalam penelitian ini terdapat fitur kendali yaitu kendali satu lampu yang digunakan untuk menghidupkan satu lampu dan kendali dua digunakan untuk menghidupkan lampu secara bersamaan.
\end{abstract}

Kata Kunci: Internet of thing (IoT), Raspberry Pi, Mobile

\begin{abstract}
Internet of thing (IoT) is a concept that aims to expand the benefits of internet connectivity that is connected continuously. Internet of thing (IoT) can be utilized in buildings to control electronic equipment such as room lights that can be operated remotely via computer network. This study aims to build a remote control device by utilizing internet technology to perform the process of mobile-based light control. The research was done by building a prototype and mobile based application using python programming language. In this study there is a control feature that controls one lamp used to turn on one lamp and control two is used to turn on the light simultaneously.
\end{abstract}

Keywords: Internet of thing (IoT), Raspberry Pi, Mobile 


\section{PENDAHULUAN}

Internet of thing (IoT) merupakan suatu konsep yang bertujuan untuk memperluas manfaat dari konektivitas internet yang tersambung secara terus menerus [1]. Internet of thing (IoT) bisa dimanfaatkan pada gedung untuk mengendalikan peralatan elektronik seperti lampu ruangan yang dapat dioperasikan dari jarak jauh melalui jaringan komputer, tidak dapat dipungkiri kemajuan teknologi yang sedemikian cepat harus bisa dimanfaatkan,dipelajari serta diterapkan dalam kehidupan sehari-hari. Contohnya adalah perkembangan teknologi yang bisa dimanfaatkan dari adanya koneksi internet ini bisa mengakses peralatan elektronik seperti lampu ruangan yang dapat dioperasikan dengan cara online melalui mobile. Sehingga, dapat memudahkan pengguna memantau ataupun mengendalikan lampu kapanpun dan dimanapun dengan catatan di lokasi yang akan diterapkan teknologi kendali jarak jauh mempunyai jaringan internet yang memadai. Sistem kendali jarak jauh, memudahkan pengguna dalam mengontrol lampu gedung yang jaraknya cukup jauh lokasinya.

Sementara pada penelitian yang lain [2] “ Purwa Rupa Internet Of Things ( IoT ) Kendali Lampu Gedung" Teknologi sistem kendali ini dilakukannya dari sebuah komputer saja yang didalamnya terdapat sebuah sistem atau fitur software yang telah dibangun dan dirancang untuk melakukan tugas kendali tersebut terhadap lampu ruangan.Dalam pengembangan dan perbaikan terhadap permasalahan diatas, maka pada penelitian ini peneliti menggunakan Raspberry Pi 3 . Raspberry $P i$ adalah salah satu komponen Internet of Things ( IoT ) yang dapat diaplikasikan sebagai pengendali jarak jauh dengan jaringan internet yang dapat diterapkan pada peralatan elektronik seperti lampu. Perangkat tersebut dapat diakses dengan layanan internet melalui smartphone android dengan Internet Protocol sehingga tingkat efisiensi tenaga dan waktu jam kerja petugas serta dari segi penghematan energi listrik yang digunakan. Teknologi ini tepat untuk diterapkan karena untuk memudahkan petugas dalam melakukan pekerjaan tersebut.

Berdasarkan uraian di atas, maka peneliti bermaksud untuk melakukan penelitian untuk merancang prototype dan membuat program aplikasi mobile dan python menggunakan Rasberry Pi 3 sebagai pengendali lampu jarak jauh dengan jaringan internet yang dapat diterapkan pada peralatan elektronik seperti lampu sehingga tingkat efisiensi tenaga dan waktu jam kerja petugas serta dari segi penghematan energi listrik yang digunakan.

\section{LANDASAN TEORI \\ 2.1. Internet Of Things (IOT)}

Menurut [3] Internet of Things atau dikenal juga dengan singkatan IoT, merupakan sebuah konsep yang bertujuan untuk memperluas manfaat dari konektivitas internet yang tersambung secara terusmenerus yang memungkinkan kita untuk menghubungkan mesin, peralatan, dan benda fisik lainnya dengan sensor jaringan dan aktuator untuk memperoleh data dan mengelola kinerjanya sendiri, sehingga memungkinkan mesin untuk berkolaborasi dan bahkan bertindak berdasarkan informasi baru yang diperoleh secara independen.

Internet Of Things atau sering disebut IoT adalah sebuah gagasan dimana semua benda di dunia nyata dapat berkomunikasi satu dengan yang lain sebagai bagian dari satu kesatuan sistem terpadu menggunakan jaringan internet sebagai penghubung. misalnya CCTV yang terpasang di sepanjang jalan dihubungkan dengan koneksi internet dan disatukan di rung kontrol yang jaraknya mungkin puluhan kilometer. atau sebuah rumah cerdas yang dapat dimanage lewat smartphone dengan bantuan koneksi internet. pada dasarnya perangkat IoT terdiri dari sensor sebagai media pengumpul data,sambungan internet sebagai media komuniakasi dan server sebagai pengumpul informasi yang diterima sensor dan untuk analisa.

Ide awal Internet of Things pertama kali dimunculkan oleh Kevin Ashton pada tahun 1999 di salah satu presentasinya. Kini banyak perusahaan besar mulai mendalami Internet of Things sebut saja Intel, Microsoft, Oracle, dan banyak lainnya.

Banyak yang memprediksi bahwa pengaruh Internet of Things adalah " the next big thing " di dunia teknologi informasi, hal ini karena IoT menawarkan banyak potensi yang bisa digali. Contoh sederhana manfaat dan implementasi dari Internet of Things misalnya adalah kulkas yang dapat memberitahukan kepada pemiliknya via SMS atau email tentang makanan dan minuman apa saja yang sudah habis dan harus distok lagi.

\subsubsection{Cara Kerja Internet of Things}

Konsep IoT ini sebetulnya cukup sederhana dengan cara kerja mengacu pada 3 elemen utama pada arsitektur IoT, yakni: Barang Fisik yang dilengkapi modul IoT, Perangkat Koneksi ke Internet seperti Modem dan Router Wireless Speedy seperti di rumah 
anda, dan Cloud Data Center tempat untuk menyimpan aplikasi beserta data base.

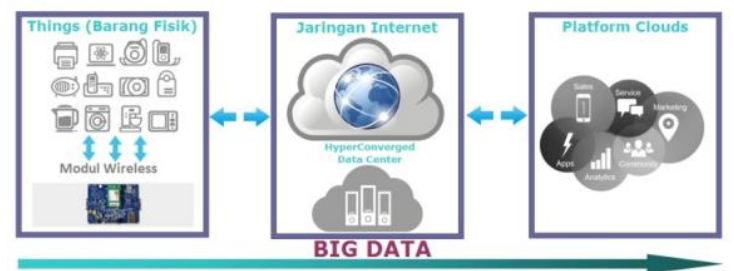

Gambar 2.1. Konsep IOT

(http://www.mobnasesemka.com/internet-of-things/)

Dasar prinsip kerja perangkat IoT adalah benda di dunia nyata diberikan identitas unik dan dapat dikali di sistem komputer dan dapat di representasikan dalam bentuk data di sebuah sistem komputer. Pada awal-awal implementasi gagasan IoT pengenal yang digunakan agar benda dapat diidentifikasi dan dibaca oleh komputer adalah dengan menggunakan kode batang (Barcode), Kode QR (QR Code) dan Identifikasi Frekuensi Radio (RFID). Dalam perkembangan nya sebuah benda dapat diberi pengenal berupa IP address dan menggunakan jaringan internet untuk bisa berkomunikasi dengan benda lain yang memiliki pengenal IP address.

Cara Kerja Internet of Things yaitu dengan memanfaatkan sebuah argumentasi pemrograman yang dimana tiap-tiap perintah argumennya itu menghasilkan sebuah interaksi antara sesama mesin yang terhubung secara otomatis tanpa campur tangan manusia dan dalam jarak berapa pun. Internetlah yang menjadi penghubung di antara kedua interaksi mesin tersebut, sementara manusia hanya bertugas sebagai pengatur dan pengawas bekerjanya alat tersebut secara langsung.

\subsubsection{Implementasi IoT}

Mesin dibuat agar pekerjaan manusia menjadi lebih mudah, pada awalnya mesin dibuat hanya untuk membantu manusia dan dioperasikan secara manual, lambat laun mesin bisa berjalan sendiri (otomatis), tetapi dalam perkembangan nya pemanfaatan mesin sebagai alat dalam sebuah sistem akan menemui kendala jika sudah menyangkut jarak dan waktu. dengan jarak yang begitu jauh maka mesin tikdak akan bisa merinteraksi dengan mesin yang lain, untuk mengatasi hal inilah diterapkan gagasan internet of things dinama semua mesin dengan pengenal IP address dapat menggunakan jaringan internet sebagai media komnukasi (Saling bertukar data).

Tabel 2.1.2 : Penerapan IoT

\begin{tabular}{|c|c|}
\hline $\begin{array}{l}\text { Implementasi IoT } \\
\text { Dalam Bidang } \\
\text { Keamanan }\end{array}$ & $\begin{array}{l}\text { Pengamanan } \\
\text { menggunakan kamera } \\
\text { CCTV di rumah, jalan dan } \\
\text { gedung dapat dikontrol } \\
\text { dimana saja }\end{array}$ \\
\hline $\begin{array}{l}\text { Implementasi IoT } \\
\text { Dalam Bidang } \\
\text { Property }\end{array}$ & $\begin{array}{l}\text { eskalator, sistem } \\
\text { pendingin gedung, sistem } \\
\text { keamanan, CCTV, sistem } \\
\text { administrasi, kelistrikan, } \\
\text { instalasi saluran air dan } \\
\text { gas dan lain sebagainya. }\end{array}$ \\
\hline $\begin{array}{l}\text { Implementasi IoT } \\
\text { dalam bidang Medis }\end{array}$ & $\begin{array}{l}\text { pemasangan sensor detak } \\
\text { jantung dan sensor yang } \\
\text { lain pada pasien yang } \\
\text { terhubung ke ruang pusat } \\
\text { kontrol untuk memonitor } \\
\text { keadaan pasien secara } \\
\text { otomatis dan memberikan } \\
\text { peringata jika terjadi hal } \\
\text { buruk,sistem pembayaran } \\
\text { rumah sakit dll. }\end{array}$ \\
\hline
\end{tabular}

\subsection{Aplikasi Mobile}

Aplikasi Mobile adalah perangkat lunak yang berjalan pada perangkat mobile seperti smartphone atau tablet PC [4]. Aplikasi Mobile juga dikenal sebagai aplikasi yang dapat diunduh dan memiliki fungsi tertentu sehingga menambah fungsionalitas dari perangkat mobile itu sendiri. Untuk mendapatkan mobile application yang diinginkan, user dapat mengunduhnya melalui situs tertentu sesuai dengan sistem operasi yang dimiliki. Google Play dan iTunes merupakan beberapa contoh dari situs yang menyediakan beragam aplikasi bagi pengguna Android dan iOS untuk mengunduh aplikasi yang diinginkan.

Maka aplikasi mobile dapat di artikan sebuah program aplikasi yang dapat dijalankan atau digunakan walaupun pengguna berpindah - pindah dari satu tempat ke tempat yang lain serta mempunyai ukuran yang kecil. Aplikasi mobile ini dapat di akses melalui perangkat nirkabel, pager, PDA, telepon seluler, smartphone, dan perangkat sejenisnya.

\subsubsection{Android}

Menurut (Warangkiran, Kaunang, Lumenta, \& St, 2014), Android adalah sistem operasi untuk telepon seluler yang berbasis Linux. Android utamanya adalah produk Google, tetapi lebih tepatnya bagian dari Open Handset Alliance. Open Handset Alliance merupakan aliansi dari 30 organisasi yang berkomitmen untuk membawa sebuah perangkat seluler yang lebih baik dan terbuka untuk pasar. Android termasuk kernel berbasis Linux, aplikasi end-user, dan framework aplikasi. User application dibangun berbasiskan bahasa pemrograman 
Java. Bahkan aplikasi yang dibangun juga berbasiskan Java.

\subsection{Unified Modeling Language}

UML merupakan bahasa visual dalam pemodelan yang memungkinkan pengembang sistem membuat sebuah blueprint yang dapat menggambarkan visi mereka tentang sebuah sistem dalam format yang standar, mudah dimengerti, dan menyediakan mekanisme untuk mudah dikomunikasikan dengan pihak lain [5].

\subsubsection{Use Case}

Use case adalah suatu pola atau gambaran yang menunjukan kelakukan atau kebiasaan system [5].

Menurut Roger Pressman (2011, p847) Use Case Diagram menggambarkan bagaimana user berinteraksi dengan sistem dengan cara mendefinisikan langkahlangkah yang dibutuhkan untuk menyelesaikan tujuan tertentu.

Sebuah format yang mudah untuk membuat sebuah use case adalah dengan menjelaskan skenario utamanya sebagai sebuah urutan langkah-langkah dan alternatif langkah-langkah sebagai variasi dari urutan tersebut.

\section{METODOLOGI PENELITIAN}

Adapun kerangka kerja dalam penelitian ini sebanyak 4 tahapan yang digambarkan berikut ini:

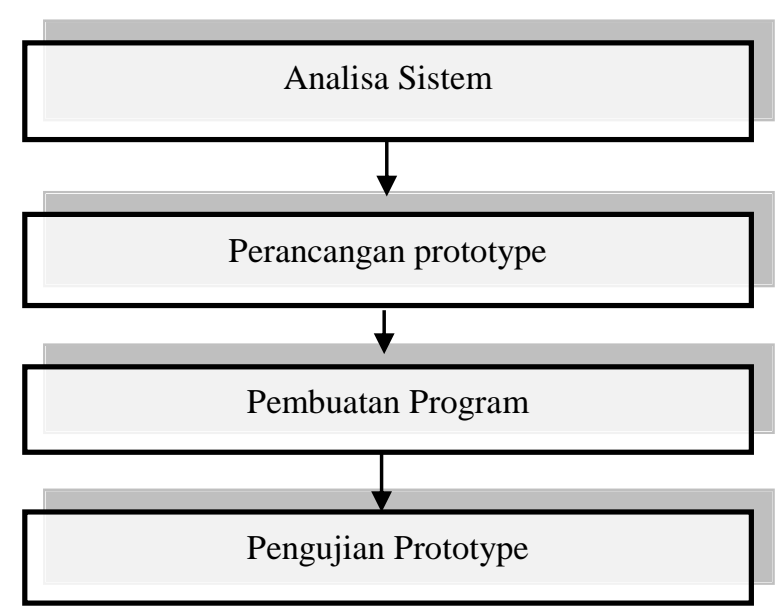

Gambar 3.1. Metodologi Penelitian

Berdasarkan kerangka kerja diatas, maka masing - masing tahapan tersebut dapat dijelaskan sebagai berikut :

\subsection{Analisa Sistem}

Copyright (C) 2018 FIKOM - UNASMAN

http://ejournal.fikom-unasman.ac.id
Analisis kebutuhan sistem ini ditujukan untuk menguraikan kebutuhan-kebutuhan yang harus disediakan oleh sistem agar dapat memenuhi kebutuhan pengguna dan sesuai dengan tujuan penelitian yaitu melakukan perancangan Sistem Pengendalian Lampu Berbasis Mobile. Rancangan sistem ini menjelaskan kebutuhan antarmuka, kebutuhan data masukan dan data keluaran yang menunjukkan spesifikasi sistem yang dapat diakses.

\subsubsection{Analisa Fungsional}

Analisa Kebutuhan fungsional merupakan gambaran mengenai fungsi-fungsi yang dapat dilakukan oleh sistem ini. Kebutuhan fungsional sistem meliputi:

a. Sistem yang dirancang berbasis mobile.

b. pada sistem mobile harus terinstal di smartphone.

c. Adanya fasilitas mematikan lampu per ruangan dan keseluruhan lampu secar bersamaan.

\subsubsection{Analisa Non Fungsional}

Analisa Kebutuhan non-fungsional adalah kebutuhan sistem meliputi kinerja, kelengkapan operasi pada fungsi-fungsi yang ada, serta kesesuaian dengan lingkungan penggunanya. Kebutuhan non-fungsional ini melingkupi beberapa kebutuhan yang mendukung kebutuhan fungsional, rumusan kebutuhan nonfungsional meliputi:

a. Kebutuhan Operasional

- Pada sistem mobile, aplikasi dapat terinstal pada perangkat Android. .

- Pada sistem mobile, sistem hanya dapat diakses melalui file format apk yang telah terinstal di perangkat Android.

- Aplikasi dapat dijalankan pada minimal Android versi 4.2 (Jelly Bean).

- User interface pada aplikasi dibuat dengan sederhana untuk memudahkan pengguna

\section{b. Performance Sistem}

Sistem yang dibangun merupakan aplikasi yang berjalan pada lingkungan perangkat bergerak. Terdapat beberapa keterbatasan yang ditemui pada perangkat. Oleh karena itu perlu diperhatikan guna menjadi acuan dalam pengembangan sistem, diantaranya:

- Sumber daya listrik digunakan se efektif mungkin.

- Tampilan aplikasi antarmuka disesuaikan dengan kebutuhan.

- Merancang aplikasi dengan antarmuka yang sederhana namun tetap menarik dan mudah digunakan oleh pengguna.

\subsection{Perancangan Prototype}

Dalam membuat rancangan Prototype sesuai data yang ada berdasarkan tahapan yang ditetapkan pada tahapan analisa data. Diperlukan rancangan use 
case sistem pengendalian lampu berbasis mobile.

\subsection{Pembuatan Program}

Membuat sebuah aplikasi dengan berbasiskan

Rasberry Pi 3 dalam pengedalian lampu berbasis Mobile.

\subsection{Pengujian Prototype}

Menguji seluruh spesifikasi terstruktur dan aplikasi secara keseluruhan. Pada tahap ini dilakukan uji coba aplikasi yang telah selesai dibuat. Proses uji coba ini diperlukan untuk memastikan bahwa aplikasi yang telah dibuat sudah benar, sesuai dengan karakteristik yang ditetapkan dan tidak ada kesalahan yang terkandung didalamnya.

\section{HASIL PENELITIAN}

\subsection{Perancangan Protype}

Perancangan Protype Pengendalian Lampu Berbasis Mobile dimulai pemakain DT Relay seperti gambar berikut:

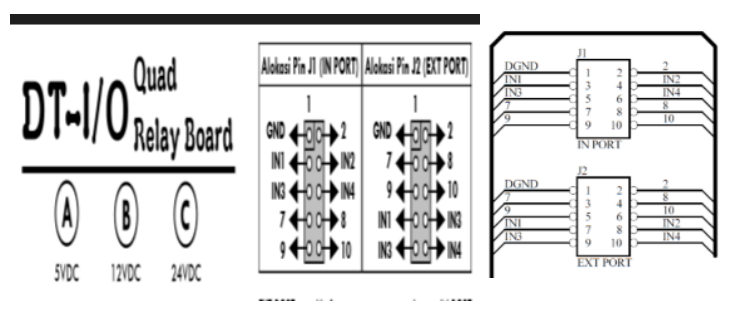

\section{Gambar 4.1 Koneksi DT-Relay}

Setelah DT- Relay, dilanjutkan mengatur Data Sheet Raspberry Pi 3 dengan tampilan seperti gambar berikut:

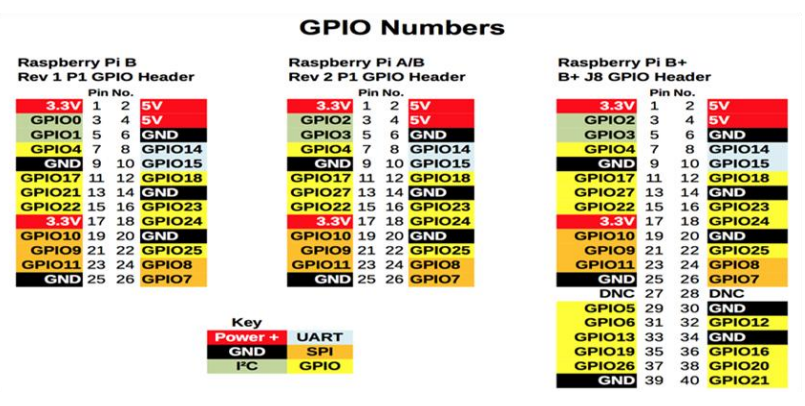

\section{Gambar 4.2 Raspberry Pi 3}

Maka akan tampil, koneksi prototype DTRelay dengan Raspberry Pi 3 yang terhubung dengan menggunakan kabel pelangi. Tampilan sebagai berikut
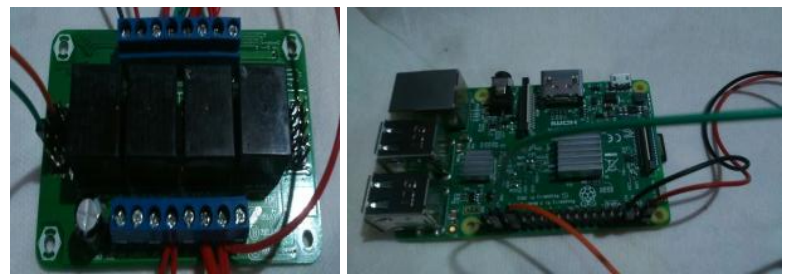

Gambar 4.3 DT-Relay-Raspberry Pi 3

Setelah koneksi DT-Relay dan Raspebery Pi 3 terkoneksi lalu persiapkan 2 fitting lampu dengan bola lampu. Untuk tampilan lebih baik bisa kita gunakan akrilik untuk membatasi antara ruang lampu yang satu dengan yang lainnya. Dapat dilihat pada gambar berikut:

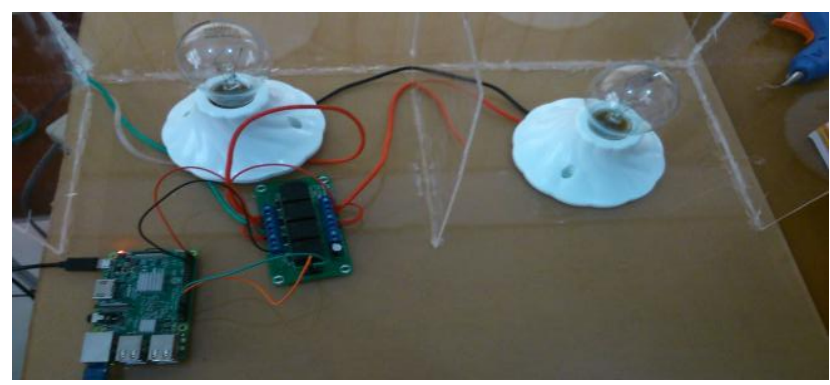

Gambar 4.4 DT-Relay-Raspberry Pi 3- 2 Fitting Lampu dengan Akrilik pembatas

\subsection{Pembuatan Program}

Dalam pembuatan program, kami mengacu pada usecase yang digunakan dalam sistem pengendalian lampu berbasis mobile. Tampilan use case sebagai berikut:

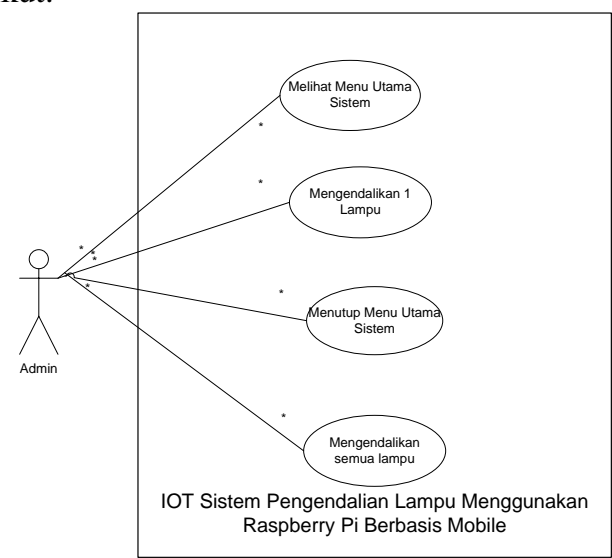

\section{Gambar 4.5 Use case Sistem Pengendalian Lampu berbasis Mobile}


Rancangan Desain tampilan pada mobile sebagai berikut:

IOT Sistem Pengendalian Lampu Menggunakan Raspberry Pi 3 berbasis Mobile

Bola Lampu 1

Bola Lampu 2

\section{Gambar 4.6 Tampilan Perangkat Mobile}

Langkah selanjutnya, dilakukan konfirgurasi script menggunakan bahasa pemogram pyhton. Dapat dilihat sebagai berikut:

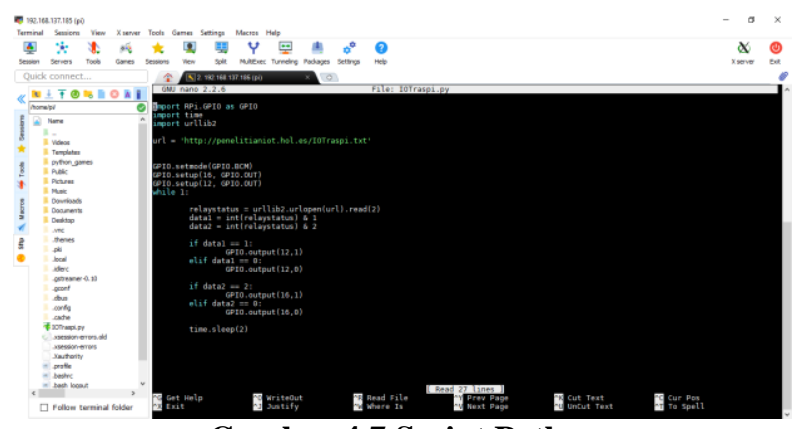

Gambar 4.7 Script Python

\subsection{Implementasi}

Pada sistem ini, dibangun untuk dapat menampilkan infromasi pengedalian lampu yang nantinya akan langsung oleh petugas menggunakan aplikasi berbasis mobile. Berikut ini tampilan aplikasi pengendalian lampu:

\subsubsection{Tampilan sistem pengendalian lampu berbasis} Mobile

1. Tampilan perangkat mobile posisi lampu mati semua. MOBILE
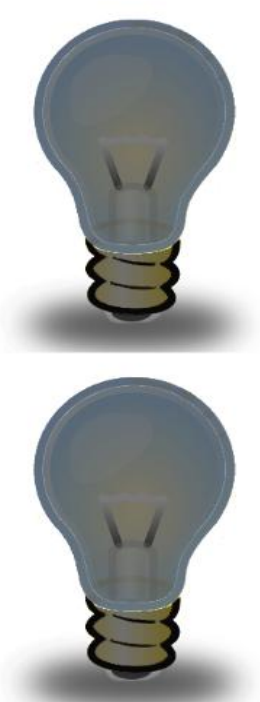

Gambar 4.8. Tampilan mobile posisi lampu mati semua

2. Tampilan perangkat mobile posisi 1 bola lampu menyala 


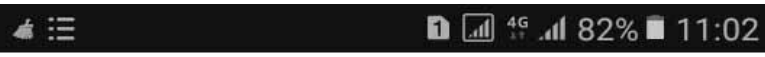

\section{SISTEM PENGENDALI LAMPU BERBASIS MOBILE}

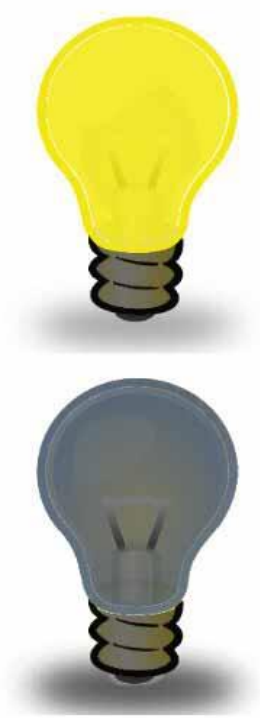

Gambar 4.9. Tampilan mobile posisi 1 bola lampu menyala

3. Tampilan perangkat mobile posisi bola lampu ke 2 menyala

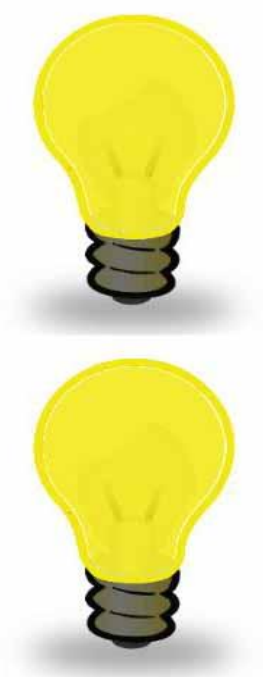

Gambar 4.10. Tampilan mobile posisi bola lampu ke 2 menyala

\section{Kesimpulan dan Saran}

\subsection{Kesimpulan}

1. Rancangan Prototype pengendalian lampu ini hanya digunakan untuk menyalakan, mematikan, dan memonitoring lampu.

2. Pengendalian lampu ini hanya didukung perangkat mobile menggunakan android.

3. Internet of Things (IoT) telah diterapkan pada proses pembelajaran mata kuliah mobile computing dan mikroprosessor.

\section{Ucapan Terimakasih}

Terimakasih kepada Yayasan Komputasi Riau yang dan STMIK Amik Riau telah mendukung serta terimakasih juga kepada LPPM STMIK Amik Riau yang telah memfasilitasi sehingga penelitian ini dapat terlaksana dengan baik. 


\section{DAFTAR PUSTAKA}

[1] Panduardi, F., \& Haq, E. S. (2016). Wireless Smart Home System Menggunakan Raspberry Pi. Jurnal Teknologi Informasi Dan Terapan, 3(1), 320-325.

[2] Kurniawan. (2016). Purwarupa IoT (Internet Of Things) Kendali Lampu Gedung (Studi Kasus Pada Gedung Perpustakaan Universitas Lampung), 57.

[3] Arafat, M. K. (2016). SISTEM PENGAMANAN PINTU RUMAH BERBASIS Internet Of Things ( IoT ) Dengan ESP8266. Jurnal Ilmiah Fakultas Teknik "Technologia," 7(4), 262-268.

[4] Irsan, M. (2015). Rancang Bangun Aplikasi Mobile Notifikasi Berbasis Android untuk Mendukung Kinerja di Instansi Pemerintahan, 1(1). Retrieved from http://jurnal.untan.ac.id/index.php/justin/article/vi ew/9984/9752

[5] Simaremare, Y. P. W., Pribadi, A., \& Wibowo, R. P. (2013). Perancangan dan Pembuatan Aplikasi Manajemen Publikasi Ilmiah Berbasis Online pada Jurnal SISFO. Jurnal Teknik ITS, 2(3), 470475. Retrieved from http://ejurnal.its.ac.id/index.php/teknik/article/vie w/5163/1552

[6] Warangkiran, I., Kaunang, I. S. T. G., Lumenta, A. S. M., \& St, A. M. R. (2014). Perancangan Kendali Lampu Berbasis Android. E-Jurnal Teknik Elektro Dan Komputer, 1, 1-8.

[7] Hastanti, R. P., Eka, B., Indah, P., \& Wardati, U. (2015). Sistem Penjualan Berbasis Web ( ECommerce ) Pada Tata Distro Kabupaten Pacitan. Jurnal Bianglala Informatika, 3(2), 1-9

http://teknojurnal.com/definisi-internet-of-things/ http://daily.oktagon.co.id/lima-impelementasi-internetof-things-dalam-kehidupan-sehari-hari/

http://www.academia.edu/12418429/PENGERTIAN_I NTERNET_OF_THINGS

http://www.mobnasesemka.com/internet-of-things/ 